\title{
COMPUTER TEACHERS' AWARENESS OF VIRTUAL REALITY FOR INSTRUCTIONAL PURPOSE IN KWARA STATE
}

\author{
Aderonke Kofo Soetan \\ Department of Educational Technology, Faculty of Education, University of Ilorin, Ilorin, Nigeria \\ E-mail: akdof2015@gmail.com \\ Amos Ochayi Onojah \\ Department of Educational Technology, Faculty of Education, University of Ilorin, Ilorin, Nigeria. \\ E-mail: haymoresonojah@gmail.com \\ Adenike Janet Aderogba \\ Department of Educational Technology, Faculty of Education, University of Ilorin, Ilorin, Nigeria. \\ E-mail: temiladeadenike2015@gmail.com \\ Omotayo Olabo Obielodan \\ Department of Educational Technology, Faculty of Education, University of Ilorin, Ilorin, Nigeria. \\ E-mail: tayoobielodan@unilorin.edu.ng \\ Olanrewaju Sulaimon Ganiyu \\ Department of Educational Technology, Faculty of Education, University of Ilorin, Ilorin, Nigeria. \\ E-mail: ganiyuos@gmail.com \\ Micheal Ayodele Fakomogbon \\ Department of Educational Technology, Faculty of Education, University of Ilorin, Ilorin, Nigeria. \\ E-mail: dele@unilorin.edu.ng
}

APA Citation: Soetan, A. K., Onojah, A. O., Aderogba, A. J., Obielodan, O. O., Ganiyu, O. S.,\& Fakomogbon, M. A. (2020). Computer teachers' awareness of virtual reality for instructional purpose in Kwara State. Indonesian Journal of Learning and Instruction, 3(1), 1-10. doi: 10.25134/ijli.v3i1.3002.

\begin{abstract}
Virtual reality is an emerging technology designed to provide interaction between a user and artificially generated environments. However, most teachers in Nigeria are not aware of how virtual reality can be widely used for educational purposes. The study investigated (i) awareness of teachers towards the use of virtual reality for instructional purpose and influence of gender and experience on teachers' awareness of virtual reality for instructional purpose. Descriptive survey research design was adopted for this study. 360 computer teachers were sampled from secondary schools across Kwara State with the use of researchsdeveloped questionnaire. The findings established that Virtual Bicycle and 3D Map world are the virtual reality facilities which most respondents are of aware for instructional purpose; and there was no significant difference between teachers' awareness of VR for instructional purpose based on gender and experience. It was thus recommended that seminars and training could also be organised for teachers on how to use VR to facilitate their teaching in and outside the classroom environment.
\end{abstract}

Keywords: awareness; computer teachers; virtual reality; gender; experience; instructional purposes.

\section{INTRODUCTION}

The impact of information and communication technologies (ICT) on education is gaining its popularity across all sectors including the educational system. In order to fulfill the Vision 2020 of Nigeria, the educational system has to be transformed and driven by ICT because the use of ICT to facilitate the educational process saves time, money and energy. information and communication technology (ICT) and information technology (IT) can be used interchangeably. Information can be seen as "idea" conceived in the human mind, while communication is the transfer of that information from the original source to the destination where it is needed with the intention to producing a change in behavior of the receiver (Adekomi, 2014). Thus, ICT is becoming increasingly influential factor that could facilitate and speed up the transformation expected in education. ICT is an umbrella term that includes any communication device or application, encompassing: radio, television, cellular phones, computer, and network hardware and software, satellite systems and so on, as well 
Aderonke Kofo Soetan, Amos Ochayi Onojah, Omotayo Janet Aderogba, Omotayo Olabo Obielodan, Olanrewaju Sulaimon Ganiyu, \& Micheal Ayodele Fakomogbon

Computer teachers' awareness of virtual reality for instructional purpose in Kwara State

as the various services and applications associated with them, such as videoconferencing and distance learning (Bhattacharya \& Sharma, 2017). The need for technological innovation has brought a revolution in development of technological application in education. This has contributed to the development of educational systems. Educators are fast realizing that the use of computer assisted teaching and learning could be convenient for the users (Ebrahimi, 2016). The growth of technologies is based on world's development in all aspects. As a result, the need for the use of Information Communication Technologies (ICT) in teaching/learning is inevitable (Idrus \& Salleh, 2017).

The benefits of ICT being nature-protecting, non-polluting, less energy consumption and above all, more human-friendly, it is applications are becoming indispensable parts of contemporary culture, spreading across the globe through general and vocational education (Ogunlade, Olafare, \& Udom, 2013). ICT refers to computer centred tool adopted by individual to meet information processing need of an organization. ICT incorporate facilities such as radio, video, television, computers, hardware and firmware, as well as approaches, practices, procedures, concepts and principles that are used in the conduct of information and communication activities as well as imparting knowledge to the learners. Similarly, ICT functions as a change agent on learning process, it impacted on place 'when' and 'where' to learn, improve quality of education and enhanced educational management (Kaur, 2015). ICT is all kinds of electronic systems that are used for broadcasting, telecommunications, all forms of computer mediated communication and can be used to make teaching and learning more effective (Bridget \& Comfort, 2016). Dede, Salzman, \& Loftin, (2013) stated that VR is a technology designed to provide interaction between a user and artificially generated environments. This interaction is more natural, direct, or real than pure simulation technologies or other previous technologies. The major target of VR is involving the user in the artificial environment, in order to invent the fantasy of being in an environment that can be comprehended as a realistic place with sufficient interactivity to carry out tasks in a proficient and comfortable way. There are two main stilts that illustrate the VR experience from the physical and psychological point of view: immersion and presence. VR allows leaners to acquire knowledge and skills outside the four walls of their classroom without them really feeling the gap of not be in the conventional classroom system. Virtual reality is a devise used to enable people to deal with information more easily. It provides a different way to see and experience information beside being used as a tool for model building and to enhance problem solving skills (Lee \& Wong, 2016). VR is described as a cutting-edge technology that allows learners to step through the computer screen into a 3-D interactive environment. Generally, there are two major types based on the level of interaction and immersive environment. The first category, known as immersive VR, is based on helmet mounted or immersive display technologies. The second category, nonimmersive VR, or, sometimes, desktop VR, presents images on a normal monitor and allows the user to interact with the computer-generated images. The reason for using this type of technology is the that the users can simulate any aspect of the real world and experiment safely as the digital prototypes do not pose any hazard. VR environments offer the capacity of limitless repetitions for training purposes and they are nondistractive, time and cost efficient. VR technology has been used in education to facilitate imparting knowledge and understanding as a learning aid along with traditional modalities in schools and colleges. Abdullahi (2020) examined the determinants of virtual labs adoption among physics teachers in Ilorin-west local government area of Kwara State and established that Physics teachers' perceived usefulness and ease of use of virtual laboratory have positive influence on the adoption of virtual laboratory.

The objectives of science and technology policy are in agreement with national objectives as stated under the section on the philosophy of Nigerian education. These objectives include to increase public awareness in science and technology, to direct the science and technology efforts of the nation along well defined national goals e.g. self-reliance, to promote the translation of science and technology results into goods and services, to increase and maintain an indigenous science based on research and development and to motivate and create output in science and technology as basis of the nation (FRN, 2014). Awareness is to have knowledge about the existence of VR. Teacher's awareness to a great extent shape the format of instructions and learning that students will receive in a regular classroom. Being aware about the recent technologies that can foster learning is 
significantly essential for teachers to be able to be truly disseminate classroom instruction effectively. When teachers are aware and well informed about the use of VR for instructional purposes in computer studies, they feel more confident about the roles they need to play in the classroom. The awareness, knowledge and attitudes of the teacher also impact the effectiveness in the use of Virtual reality for instructional purpose. Similarly, Msagati (2014) reported that lack of awareness and inadequate search skills were the major problems hindered academic staff from used of internet service Garrison, (2017) concluded that awareness on the inclusion of VR in computer studies curriculum cannot be used interchangeably with awareness on the use by school teachers. Teachers were not aware of the use of VR and then they are left with the option of the use of pictures as a means of instructional material. Teachers who experienced low levels of engagement with educational technology at university will most likely perceive VR as not so important when they teach their own students. Some teachers are aware of the use of VR but there is lack of opportunities for them to apply their technology skills learned during training. These issues affect not only the teaching aspect, but also the learning aspect in a technology-rich environment. Some of these teachers attribute this problem to the lack of scheduled time by school authorities, inability of the school to procure virtual realities for instructional purposes. The issue of awareness of computer teachers discussed above parallels the teaching and learning process in computer studies. From the researcher's previous experience, lack of good computer knowledge among some teachers has resulted in the technology (virtual reality) provided by some schools being underutilized. It is imperative that some teachers are aware of the technological capabilities provided by some secondary schools because they should live up to the new generation's expectations. Students are becoming more and more technology savvy (Prensky, 2015). The aim of making learning take place with the use of materials in classroom situation encompasses the teachers' instructional purpose. Dede, Salzman, and Loftin, (2013) asserted that VR has been elaborated in the field of education due to the positive outcomes that have been reported in science, engineering, business knowledge application, and anatomy learning. However, VR might not work for all kinds of learning for different reasons: the suitability of content of the material to VE, learner characteristics, VR system effectiveness, teachers' awareness of VR technology, and their perceptions toward adapting it. This study therefore aims to verify the users (computer teachers) awareness and perceptions towards the use of VR for instructional purposes.

Anaza (2017) noted that, gender differences in the use technology should be carefully examined, rather than merely demonstrating differences. The influence of gender in classroom utilization of technology also plays a major role in the selection, development and achievement of instructional objectives. Van Braak (2019) proposes that female students exude lower confidence or knowledge ability than males about using computers. Among the factors that need attention in online assessment research are gender, level of education and computer usage level. On the other hand, Rajasekhar, Veena and Kumar (2018) reported that there was significant difference on the preferred accessed of website among respondents based on gender. The inclusion of gender into attitude research as a factor is quite widespread for the simple reason that it may have a differential effect on results, complicating the plain interpretation of findings, favouring one over the other Bahah and Asil (2018). Undoubtedly, the full participation of both male and female teachers in the use of virtual reality will increase the positive impact of these technologies thereby improving their job performance. However, maximizing such participation of male and female in using search engines can lead to gender inequity (United Nations) (UN, 2014). There is need to investigate if computer teachers use of technologies differ based on their gender. Whether a digital gender gap persists, or is disappearing with the maturation and diffusion of ICT is still under debate (Leach \& Turner, 2015). Furthermore, Abdullahi (2020) deduced that ender does not influence the adoption of virtual laboratory for teaching among physics teacher.

The findings of Mahdi and Al-Dera (2013) revealed that there is no significant difference in ICT use regarding teachers' teaching experience. The basis for all learning is experience, and usually the most effective type of learning is gained by concrete, direct, first-hand experience. Sawchuk (2015) asserted that experienced teachers got better in motivating students to learn with electronic media and with classroom management, resulting in better attendance and fewer infractions. The experienced teacher, 
Aderonke Kofo Soetan, Amos Ochayi Onojah, Omotayo Janet Aderogba, Omotayo Olabo Obielodan, Olanrewaju Sulaimon Ganiyu, \& Micheal Ayodele Fakomogbon

Computer teachers' awareness of virtual reality for instructional purpose in Kwara State

however, realizes that the use of words alone cannot and will not, provide vivid learning experience. Usang, Archibong, Aji, Eyong, Ukam and Bassey (2018) noted that application of technologies in teaching and learning has raised education to a new phase by improving the quality of education in the world. Vlastimir and Dalibor (2019) also asserted that Integrating ICT into Education has improve knowledge in the field of interpretation, not only in the learning process, but also for future professional activity. The use of the web as an educational tool has provided teachers with a wide range of new and exciting teaching experiences that are not possible in traditional classroom (Nam \& Smith-Jackson, 2017). Good teachers are constantly introducing methods and devices that will make learning meaningful as teachers who use technologies are gradually replacing teachers who do not. Experience refers to the nature of the events of someone or something undergone. The theoretical basis for this study is grounded on the Theory of Diffusion of Innovations propounded by Rogers (1995). This theory will help to establish if teachers who are aware of this virtual reality will accept or embrace the innovation. The Theory of Diffusion of Innovations is used to describe the adoption or acceptance of a new innovation among several adopter groups. It incorporates the impact of social dynamics on technology adoption. Lorenzo (2019) stated that experience is not interesting till it begins to repeat itself. Experience is an event, act or thing that one has seen, done or felt. It can be a situations or job done for a long time or some action done by one repeatedly that has almost become part of one.

The importance of technology into the teaching and learning process cannot be overemphasized. There is an urgent need to improve the quality of education to bridge the gap between developed and developing nations. Technological advancements have created opportunities for the augmentation and or complete replacement of physical science laboratories in the teaching of science graduates. However, the acceptability and suitability of these alternatives have remained contentious issues and only the bravest and most liberal institutions have so much as dared to discuss let alone try to incorporate them in their curricular. There is a need, at this juncture, to explore the suitability and acceptability of virtual laboratories as potential alternatives or supplements to the expensive traditional physical laboratory facilities in the third world context. However, using virtual

labs by teachers for teaching needs a high level of professionalism and commitment because it is new in this part of our world. By doing this there are certain things that will determine this usage by teachers such as training, environment, experience among others. Mahmood, Halim, Rajindra and Ghani (2014) reported that lack of exposure and expertise on part of teachers, forcing of teachers to use technology without giving them ample time to learn, acquire and apply the technology appropriately and lack of confidence among teachers which again is attributed to lack of professional training are the barriers to the utilization of Internet facilities. Ausburn and Ausburn (2014) conducted a research on Desktop virtual reality: A powerful new technology for teaching and research in industrial teacher education and established virtual reality will influence teachers job performance if effectively utilized. Though the relevance of materials cannot be overemphasized, but teachers lack its application in the classroom and lack of fund to purchase relevance ones. Soetan, Onojah, Alaka, and Aderogba (2020) examined hearing impaired students' self-efficacy on the utilization of assistive technology in federal college of education (special) Oyo and established that technology enhances students' self-efficacy beacuse motivating students with learnings, give them sense of belonging so that they could also partake in things around their vicinity effectively. Although, there are studies conducted on teachers use of virtual reality for instructional purposes but most of it are in developed countries as this innovation is still very new in Nigeria. Also, none of such studies has been conducted in Kwara state that the researchers are aware of. This research tends to fill this gap by investigating teachers' awareness of virtual reality for instructional purpose in computer studies. This research investigated the teachers' awareness of virtual reality for instructional purpose in computer studies. Specifically, this study determined the awareness of teachers towards the use of VR for instructional purpose; influence of gender on teachers' awareness of VR for instructional purpose and the influence of teachers' experience on awareness of VR for instructional purpose.

The following questions were raised to guide the study:

1. What is the level of awareness of teachers towards the use of VR for instructional purpose? 
2. Does gender influence teachers' awareness of VR for instructional purpose?

3. How do teachers' experience influence their awareness of VR for instructional purpose?

The following hypotheses were formulated and tested in this study:

$\mathbf{H}_{01}$ : There is no significant difference between male and female teachers' awareness of VR for instructional purpose?

$\mathbf{H}_{02}$ : There is no significant difference between teachers' experience and their awareness of VR for instructional purpose.

\section{METHOD}

Descriptive survey research design was used to obtain information concerning the current status of the phenomena in this study. The population for the study consisted of all the computer teachers in Kwara state. The study investigates the Awareness of teachers on the use of virtual reality for instructional purpose in computer studies. Purposive sampling technique was used to select the schools in the case study area. While simple random sampling technique was used to select a total of 360 computer studies teachers from the selected schools. A research-designed questionnaire was used to obtained necessary information from the respondent. The instrument that was used for this study was a researcherdesigned questionnaire. It consists of two sections, sections A and B. Section (A) of the questionnaire sought or solicits for teacher's demographic data which includes gender, teaching experience and name of school while Section B generated items on teachers' awareness of virtual reality for instructional purpose in computer studies. Ten different items were generated for this section. The response mode of Yes and No was used for this section.

An instrument is considered valid only when it measures truly and accurately what it intends to measure. In this case, content / face validity of the instrument was done by presenting it to the three professors of educational technology as an expert for clarity, appropriateness, and commensuration of the questions with the topic of the research and other necessary criteria to ensure validity and reliability of the instrument. The instrument was validated by three (3) other experts from the Department of Educational Technology, University of Ilorin for face and content validity and they perused it. Their comments and corrections were used to produce the final draft of the research instruments. Also, the instrument was trial tested on 20 computer studies teachers in secondary schools in Orokam, Benue state, the data collected was subjected to crombach alpha statistical analysis and the result was 0.80 on awareness.

The researchers personally administered the questionnaire to the respondents after a letter of introduction was taking to the authorities of all the sampled schools for permission to conduct the study in their schools accordingly. Explanation was equally done by the researchers on how to respond to the questionnaire before respondents were asked to respond to items and/or statement on the questionnaire. The questionnaire was administered to the purposively selected computer teachers in the selected schools. The completed questionnaires were collected by the researchers on the spot. This help in ensuring a high percentage of returns. The data taken from the respondents were carefully examined and scrutinized by the researcher. The careful distribution of the survey questionnaires was managed by the researchers. Based on research ethics and to ensure high standards of professionalism, teachers' consent were sought for through research consent forms that were presented to them. Teachers participated voluntarily in the study and there was no coercion of any sort. The respondents were told to freely partake or withdraw at any time without any repercussions. Also, confidentiality of the participants was not compromised in preventing insecurity that could be felt by any participant.

Responses from the respondents were calculated in percentages followed by detailed interpretation. Research questions were analyzed using descriptive statistics of percentage, frequency and mean count while the hypothesis one was analyzed using Independent Sample Ttest, while hypotheses two was analyzed using Analysis of variance. The analysis was done through the aid of Statistical Package for Social Science (SPSS, version 25.0).

\section{RESULTS AND DISCUSSION}

This section presents the results obtained from the data gathered based on research questions stated in the study as well as discussions of findings. The data presented provide a summary of the major characteristics of the respondents that were involved in the study. A total of 360 copies of questionnaires were distributed but 321 were retrieved, properly filled and was rendered valid amounting to $89.1 \%$ return rate. This was thus used for the analysis.

\section{Demographic information}


Aderonke Kofo Soetan, Amos Ochayi Onojah, Omotayo Janet Aderogba, Omotayo Olabo Obielodan, Olanrewaju Sulaimon Ganiyu, \& Micheal Ayodele Fakomogbon

Computer teachers' awareness of virtual reality for instructional purpose in Kwara State

As displayed in Table 1, the female respondents further shown in Figure 1.

were more than their male counterparts. This was

Table 1. Demographic distribution by gender

\begin{tabular}{lccc}
\hline Gender & Frequency & Percent & Cumulative Percent \\
\hline Male & 120 & 37.4 & 37.4 \\
Female & 201 & 62.6 & 62.6 \\
Total & 321 & 100.0 & \\
\hline & & & \\
& & & \\
& & & \\
& & & \\
& & & \\
& & & \\
& & & \\
& &
\end{tabular}

Figure 1. Pie chart on respondents' gender

Table 2. Demographic distribution by respondents' years of experience

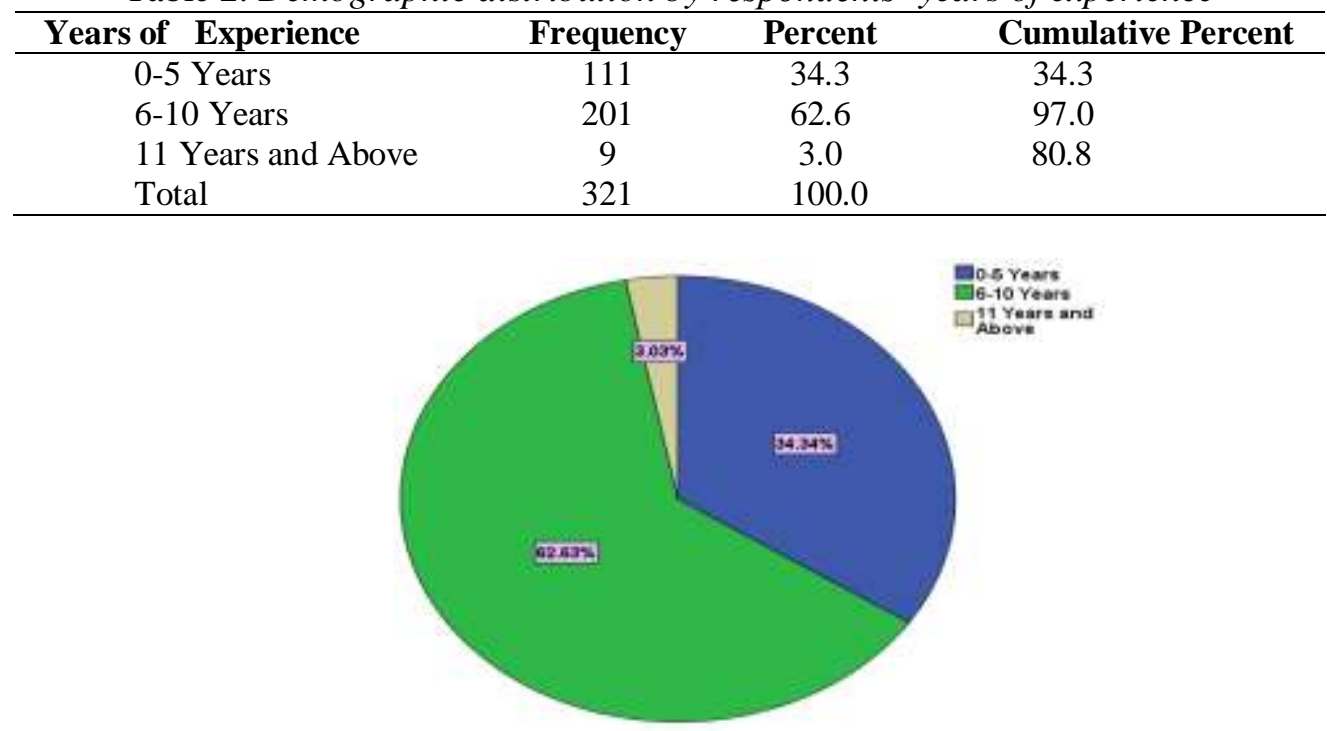

Figure 2. Pie chart on respondents' years of experience

The respondents' years of experience was analysed as shown in table 2 and figure 2 . It revealed that majority of the respondents have 610 years of experience.

\section{Research question one}

What is the level of awareness of teachers towards the use of virtual reality for instructional purpose.

Table 3. Teachers' awareness of virtual reality

\begin{tabular}{cccc}
\hline S/N & Items & Aware & Not aware \\
\hline 1 & Conceptual Design Space (CDS) & $40(37.3 \%)$ & $67(62.7 \%)$ \\
2 & Virtual Bicycle & $85(79.4 \%)$ & $22(20.6 \%)$ \\
3 & Vitcher (I \& II) & $15(14.0 \%)$ & $92(86.0 \%)$ \\
4 & Virtual Biplane & $9(8.4 \%)$ & $98(91.6 \%)$ \\
5 & 3D Map world & $56(52.3 \%)$ & $51(47.7 \%)$ \\
\hline
\end{tabular}

The level of awareness of teachers towards the use of virtual reality for instructional purpose was investigated and the result presented in table 3. It indicated that $37.3 \%$ of the respondents are aware of Conceptual Design Space (CDS), 79.4\% of the respondents are aware of Virtual Bicycle, $14.0 \%$ of the respondents are aware of Vitcher (I $\&$ II), $8.4 \%$ of the respondents are aware of 
Virtual Biplane and $52.3 \%$ of the respondents are aware of 3D Map world.

The finding established that Virtual Bicycle and 3D Map world are the virtual reality facilities which most respondents are aware for instructional purpose.

\section{Hypothesis one}

There is no significant difference between male and female teachers' awareness of virtual reality for instructional purpose In other to investigate whether there was significant difference between male and female teachers' awareness of virtual reality for instructional purpose, t-test was used to test the hypothesis at 0.05 significant level.

Table 4. $t$-test on significant differences between male and female awareness of VR

\begin{tabular}{llrrrrrrr}
\hline S/N & Gender & \multicolumn{1}{l}{ N } & \multicolumn{1}{c}{ Mean } & Std. Dev. & Df & T & Sig. (2tailed) & Remarks \\
\hline 1. & Male & 120 & 1.56 & .77 & & & & \\
& & & & & 319 & .61 & 0.87 & Accepted \\
2. & $\begin{array}{l}\text { Female } \\
\text { Total }\end{array}$ & 201 & 1.66 & .68 & & & & \\
\hline
\end{tabular}

Table 4 indicates that $\mathrm{t}(319)=0.61, \mathrm{p}=0.87$. and female teachers' awareness of virtual reality This means that the stated null hypothesis was not for instructional purpose.

rejected. This was as a result of the $\mathrm{t}$-value of 0.61 Hypothesis Two

resulting in 0.87 significance value which was There is no significant difference between greater than 0.05 alpha value. It was deduced that teachers' experience and their awareness of there was no significant difference between male virtual reality for instructional purpose.

Table 5. ANOVA on significant difference on awareness of VR

\begin{tabular}{lrrrrrr}
\hline Source & \multicolumn{1}{c}{$\begin{array}{c}\text { Type III Sum of } \\
\text { Squares }\end{array}$} & Df & \multicolumn{1}{c}{$\begin{array}{c}\text { Mean } \\
\text { Square }\end{array}$} & F & Sig. & Decision \\
\hline Corrected Model & $2.207^{\mathrm{a}}$ & 2 & 1.104 & 1.020 & .763 & \\
Intercept & 1662.689 & 1 & 1662.689 & 1537.022 & .000 & \\
Experience & 2.207 & 2 & 1.104 & 1.020 & .763 & Accepted \\
Error & 156.855 & 318 & 1.082 & & & \\
Total & 2397.680 & 321 & & & & \\
Corrected Total & 159.063 & 320 & & & & \\
\hline
\end{tabular}

a. R Squared $=.042$ (Adjusted R Squared $=.038$ )

Table 5 presents the analysis of variance showing whether there is significant difference between teachers' experience and awareness of virtual reality for instructional purpose. The result of the ANOVA table presented that null hypothesis was accepted with $\mathrm{F}(2,320)=1.10$; $\mathrm{P}$ $>0.05$. This indicated that there was no significant difference between teachers' experience and their awareness of virtual reality for instructional purpose.

The findings established that Virtual Bicycle and 3D Map world are the virtual reality facilities which most respondents are aware for instructional purpose. This support the findings of Bhattacharya and Sharma (2017) who stated that communication device or application, encompassing: radio, television, cellular phones, computer, and network hardware and software, satellite systems and so on, as well as the various services and applications associated with them, such as videoconferencing and distance learning.
Furthermore, Garrison, (2017) concluded that awareness on the inclusion of VR in computer studies curriculum cannot be used interchangeably with awareness on the use by school teachers. Lee and Wong, (2016) defined virtual reality as a device used to enable people to deal with information more easily. It provides a different way to see and experience information beside being used as a tool for model building and to enhance problem solving skills. VR unlike other educational tools, focuses shifts from prescribed interaction with the learning environment to environment that permits the learner to engage in various types of interaction that the system is capable of supporting. It is also found that virtual reality has the potential of being used to meet the learning needs of individual students, promote quality of education, increasing self-efficacy and independence of learning among students. Soetan, Onojah, Alaka, and Aderogba (2020) recommended that schools should employ 
Aderonke Kofo Soetan, Amos Ochayi Onojah, Omotayo Janet Aderogba, Omotayo Olabo Obielodan, Olanrewaju Sulaimon Ganiyu, \& Micheal Ayodele Fakomogbon

Computer teachers' awareness of virtual reality for instructional purpose in Kwara State

Educational Technologists that can facilitate

their perception thereby affecting teachers' use of effective use of assistive technology tools to supplement classroom teaching.

The findings further established that there was no significant difference between male and female teachers' awareness of virtual reality for instructional purpose. Walter, hunt and knapp (2016) pointed out that virtual environments have reported gender difference in favour of male on a variety of performance measures. Enoch and Soker (2016) found male college students are more comfortable with online course components and that gender was one of the most powerful predictors of spatial knowledge transfer in virtual environments. This support the findings of Punter, Meelissen, and Glas (2016) express the widespread gender gap in attitude and (perceived) competency in information literacy, but Cuadrado-Garcia, Ruiz-Molina, and Montoro-Pos (2018) found little difference, which may be a result of females' frequent use of a virtual learning environment.

Furthermore, it was established in this study that there was no significant difference between teachers' experience and their awareness of virtual reality for instructional purpose. Terlecki and Newcombe (2015) in their research concluded that males do not only perform at higher levels than females on tests of spatial and mental rotation ability, but also tend to have more spatial experiences. In support of this Pujari (2017) stated that user friendly, lack of knowledge of various search engines and familiarity with search engines are some of the reasons in which users preferred one search engine over another. Also, Nam and SmithJackson (2017) established that teaching experience influences their use of ICT for learning. Based on the findings of the study, the following implications can be drawn. The findings of this study have strong implication for teaching and learning process in Nigerian schools. It is an indication that if virtual reality facilities are made available for teachers in secondary schools, it will boost their frequency of use of such virtual reality in the teaching and learning process in the secondary schools. Internet has many benefits in academic cycle including provision of round-the-clock access to wide variety of information sources globally and the ability to discuss and share experience with colleague (Nwokedi \& Nwokedi, 2017). If VR are made available to all teachers irrespective of the demographic characteristics in terms of gender, experience and qualifications, it will increase

\section{CONCLUSION}

This research investigated the awareness of teachers towards the use of virtual reality for instructional purpose in computer studies. It was thus concluded that Virtual Bicycle and 3D Map world are the virtual reality facilities which most respondents are aware for instructional purpose. There was no significant difference between teachers' awareness of VR for instructional purposes based on gender and years of experience. With virtual reality, distance, time and other external measures is not a barrier for effective teaching and learning process.

Based on the findings and conclusion of this study, the following recommendations were made:

1. School administrators should encourage their computer teachers to use virtual reality for teaching computer studies.

2. Seminars and training could also be organised for teachers on the usefulness of VR to facilitate their teaching in and outside the classroom environment.

3. Female teachers should be encouraged to adopt VR for their teaching process as this could boost their job performance.

\section{ACKNOWLEDGEMENT}

Our sincere appreciation goes to all school heads and computer teachers in Kwara state and Benue state for their cooperation and assistance in conducting this research. We also show our immense gratitude to the professors, readers and senior lecturers in the department of Educational technology, their comments and corrections made the research instrument valid. Moreover, the effort of all authors whose work were cited in this study is highly appreciated. Lastly, the effort of Roseline Sotuminu, the CEO of Bella Events, whose contribution as a source of funding in carrying out this study is highly commendable.

\section{REFERENCES}

Abdullahi, Z. O. (2020). Determinants of Virtual Labs Adoption Among Physics Teachers in IlorinWest Local Government Area. Dissertation, Department of Educational Technology, University of Ilorin, Ilorin, Nigeria.

Adekomi, U. Y. (2014). Improving Computer Science Education. 1st Edition., Routledge Chapman and Hall, London.

Anaza, A. O. (2017). Assessment of lecturers' attitudes toward mobile technology usage for instruction 
in colleges of education in North Central, Nigeria. conference proceedings Association for Innovative Technology in Education (AITIE 2017), 67-74. Ilorin: Association for Innovative Technology in Education.

Ausburn, L. J., \& Ausburn, F. B. (2014). Desktop virtual reality: A powerful new technology for teaching and research in industrial teacher education. Journal of Industrial Teacher Education, 41(4), 33-58.

Bahar, M., \& Asil, M. (2018). Attitude towards eassessment: influence of gender, computer usage and level of education. Open Learning: The Journal of Open, Distance and e-Learning, 33(3), 221-237.

Bain, C. D., \& Rice, M. L. (2013). The Influence of Gender on Attitudes, Perception, and use of Technology. Journal of Research on Technology in Education, 39(2), 119-132.

Bhattacharya, I., \& Sharma, K. (2017). India in the knowledge economy: An electronic paradigm. International Journal of Educational Management, 21(6), 543-568.

Bridget, E. U., \& Comfort, U. (2016). Enhancing the utilization of information communication technology (ICT) among home economics lecturers in South Eastern Nigeria. Journal of Education and Practice, 7 (9), 34-39.

Cuadrado-García, M., Ruiz-Molina, M. E., \& Montoro-Pons, J. D. (2018). Are there gender differences in e-learning use and assessment? Evidence from an interuniversity online project in Europe. Procedia-Social and Behavioral Sciences, 2(2), 367-371.

Dede, C., Salzman, M. C. \& Loftin, R. B. (2013). Science Space: Virtual Realities for Learning Complex and Abstract Scientific Concepts. In Proceedings of IEEE Virtual Reality Annual International Symposium, 246-253. Retrieved from http://www.vetl.uh.edu/ScienceSpace/absvir.html

Ebrahimi, S. S., \& Jiar, Y. K. (2018). The Use of Technology at Malaysian Public High Schools. Merit Research Journal of Education and Review, 6(3), 54-60.

Enoch, Y., \& Soker, Z. (2016). Age, gender, ethnicity and the digital divide: University students' use of web-based instruction. Open Learning, 21(2), 99110. doi:10.1080/02680510600713045.

Federal Republic of Nigeria (2014). National Policy on Education. Lagos: NERDC Press

Garrison, D. R. (2017). Online Community of Inquiry Review: Social, cognitive, and teaching presence issues. Journal of Asynchronous Learning Networks, 11(1), 61-72.

Idrus, H., \& Salleh, R. (2017). Perceived self-efficacy of Malaysian ESL engineering and technology students on their speaking ability and its pedagogical implications. The English Teacher, XXXVII, 61-75.
Kaur, N. (2015). Using ICT in empowering teachers for quality education. International Journal of Scientific Research Engineering and Technology, 2(3), 8-12.

Leach, L., \& Turner, S. (2015). Computer users do gender: The co-production of gender and communications technology. Sage Open, 5(4), 51-58. doi.org/10.1/2158244015604693.

Lee, E. A., \& Wong, K. W., \& Fung, C. C. (2016). How does desktop Virtual Reality Enhance Learning Outcomes? A structural equation modeling approach. Computers \& Education, 55, 1424-1442.

Lorenzo, G. L., Biesanz, J. C., \& Human, L. J. (2019). What is beautiful is good and more accurately understood. Physical attractiveness and accuracy in first impressions of personality. Psychological Science, 21(12), 1777-1782. Retrieved from http://doi.org/10.1177/0956797610388048.

Mahdi, H. S., \& Al-Dera, A. S. (2013). The Impact of Teachers' Age, Gender and Experience on the Use of Information and Communication Technology in EFL Teaching. English Language Teaching, 6(6), 57-67. Retrieved from http://www.ccse-

net.org/journal/index.php/elt/article/viewFile/272 61/16554.

Mahmood, F., Halim, H. A., Rajindra, S. \& Ghani, M. M. (2014) Factors affecting teachers' utilization of technology in Malaysian ESL classrooms. The Malaysian Online Journal of Educational Technology. 2(2), 15-23.

Msagati, N. (2014). Awareness and use of scholarly electronic journal by members of academic staff: A case study of Der es Salaam university college of education. Library Philosophy and Practice (e-journal).1124, 1-25.

Nam, C., \& Smith-Jackson, T. (2017). Web-based learning environment: A theory-based design process for development and evaluation. Journal of Information Technology Education: Research, 6(1), 23-43.

Nwokedi, V. C. \& Nwokedi, G. I. (2017). Assessment on use of search engines by lecturers in the Faculty of Medical Sciences, university of Jos, Nigeria. Journal of Applied Information Science and Technology, 10(2), 23-32.

Ogunlade, O. O., Olafare, F. O., \& Udom, S. O. (2013). Perception of undergraduates on the role of information and communication technology in intrapreneurial education in University of Ilorin, Nigeria. The of Education in Developing Area, 21 (1), 117-123.

Prensky, S. (2015). Promoting teaching and learning in Ghanaian Basic Schools through ICT. International Journal of Education and Development using ICT, 11(2), 256-263.

Pujari, R. L. (2017). Usage of search engines among women post-graduation students: A case study of Karnataka State Women's University Bijpaur. 
Aderonke Kofo Soetan, Amos Ochayi Onojah, Omotayo Janet Aderogba, Omotayo Olabo Obielodan,

Olanrewaju Sulaimon Ganiyu, \& Micheal Ayodele Fakomogbon

Computer teachers' awareness of virtual reality for instructional purpose in Kwara State

Proceedings of $72^{\text {nd }}$ ISERD International United Nation. (2014). Measuring ICT and gender: An Conference, Bangkok, Thailand. 1-4.

Punter, R. A., Meelissen, M. R. M., \& Glas, C. A. W. (2016). Gender differences in computer and information literacy: An exploration of the performances of girls and boys in ICILS. European Educational Research Journal, 1(1), 1-19. doi:10.1177/1474904116672468.

Rajasekhar, P., Veena, C. N. \& Kumar, S. (2018). Gender differences in Internet preferences and usage pattern among medical students. National Journal of Physiology, Pharmacy and Pharmacology, 8(5), 683-686.

Sawchuk, S. (2015). New Studies Find That, for Teachers, Experience Really Does Matter. Retrieved from Education Week: http://www.edweek.org/ew/articles/2015/03/25 /new-studiesfind-that-for-teachers-experience.html.

Soetan, A. K., Onojah, A. O., Alaka, T. B., \& Aderogba, A. J. (2020). Hearing Impaired Students' Self-Efficacy on The Utilization of Assistive Technology in Federal College of Education (Special) Oyo. International Journal for Cross-Disciplinary Subjects in Education, IJCDSE, I1(1), 4245-4252. doi: 10.20533/ijcdse.2042.6364.2020.0519 Publication.

Usang, A. I., Archibong, D. O., Aji, E. E., Eyong, C., Ukam, E., \& Bassey, O. A. (2018). Assessment of influence of student perception, knowledge and area of specialization on ITC utilization for academic purposes in colleges of health technology, Calabar. International Journal of Medicine and Medical Science, 10 (3), 36-41.

Van Braak, J. (2019). Factors Influencing The Use of Computer Mediated Communication by Teachers in Secondary Schools. Computers \& Education, $36,41-57$.

Vlastimir N., \& Dalibor P., (2019). Appraisal and review of e-learning and ICT systems in teaching Process in Physica A. Statistical mechanics and its Application 513(1), 456-464. 